\title{
Application of 3D computer simulation for marine engineers as a hazard prevention tool
}

\author{
R. Cwilewicz \& L. Tomczak \\ Marine Propulsion Plant Department, Gdynia Maritime University, \\ Poland
}

\begin{abstract}
It is well established that one of the major factors of accident prevention on board is the perfect theoretical and practical knowledge possessed by engine room officers while operating engines and auxiliary equipment.

This paper describes the latest developments in 3D computer simulation applications, designated for the familiarization with marine machinery, especially taking into account the hazard mitigation aspect and the strengthening of the emergency response.

The paper includes the example of $3 \mathrm{D}$ computer simulation concerning emergency generator plant, where trainees have possibilities to develop operational skills, update their know-how and refresh emergency procedures. This installation plays a vital role in the safety on board. Thus, it is of extreme importance that trainees acquire the capacity to react in a prompt and effective manner to emergency situations.

This new 3D simulation technique especially emphasizes the relationship between the simulation and the realism of machinery operation.

The basic tasks for computer simulation in maritime education are equally described, taking into consideration the new methods and procedures for accident prevention. This papers' conclusion is that the use of $3 \mathrm{D}$ computer simulation in maritime education results in increased emergency preparedness and in consequence, leads to hazard mitigation and reduces the risk of human error in the operation and maintenance of marine equipment.
\end{abstract}

Keywords: $3 D$ computer simulation, marine engine room simulators, hazard prevention in operation and maintenance of marine machinery. 


\section{Introduction}

Nowadays, tremendous changes are taking place in computing, information technology and simulation. Maritime education and training is not isolated from such changes and ought to benefit from these tendencies.

For this reason engine room simulators are more and more used in maritime academies as a valuable asset for educational process [1]. The application of engine room simulators is also recommended by STCW 95 IMO Convention [2].

It is worthwhile mentioning that marine engine room simulators have also some basic disadvantages. Namely, they include lots of simplifications, abbreviations and schematic presentation of machinery systems as a result of the fact that they are presented only in $2 \mathrm{D}$ visualization. Hence, the trainee with perfect knowledge of simulator operation can experience serious problems with real ship power plant operation, because the graphical presentation and operating procedures of the simulator are distinct from the reality.

For this reason, manufacturers of engine room simulators begin to apply 3D graphical system's layout presentation in order to provide a machinery configuration as close as possible to reality.

The present development of personal computers, modern processors and graphical cards allows for an easy application of 3D simulation techniques. Also the tools (software) for creation of 3D applications are affordable.

The main problem in creation of $3 \mathrm{D}$ simulators is to provide for proper navigation through the system's elements [4,5]. Engine room is a complex, multi level and complicated set of sub-systems, equipment and machinery and this is a new challenge for entities creating such kind of simulators.

It is also necessary to allow for an easy and quick access to basic engine room operation (valve opening/closing, setting position of switches, push-buttons etc.). It is possible to achieve this feature by applying zoom techniques for selected elements of the system. Users of 3D simulators should also be able to observe the system's elements from pre-select specific parts of the engine room.

The navigation method through the system's element used in some simulators, by means of hardware or software type of joystick (with aheadastern, left-right movement) appears to be time consuming and ineffective.

Based on the author's experiences with the application of different types of simulators, a better solution consists in navigation by mouse cursor and zooming facilities.

The application of new 3D simulation techniques in marine engineering education shall be analysed on the examples of software type marine engine room simulators - Emergency Power Plant.

\section{Emergency Power Plant simulator's description}

The level of theoretical and practical knowledge possessed by engine room officers while operating engines and auxiliary equipment is directly linked to accident prevention on board. 
The basic role of Emergency Power Plant simulator is the familiarization with different operational modes. The more familiar the trainee is with the equipment the faster and more effective are his reactions to a state of emergency [3].

The basic role of Emergency Power Plant is to supply electric current, in case of failure of main diesel generators. Real photograph of Emergency Power Plant is presented on fig. 1 .

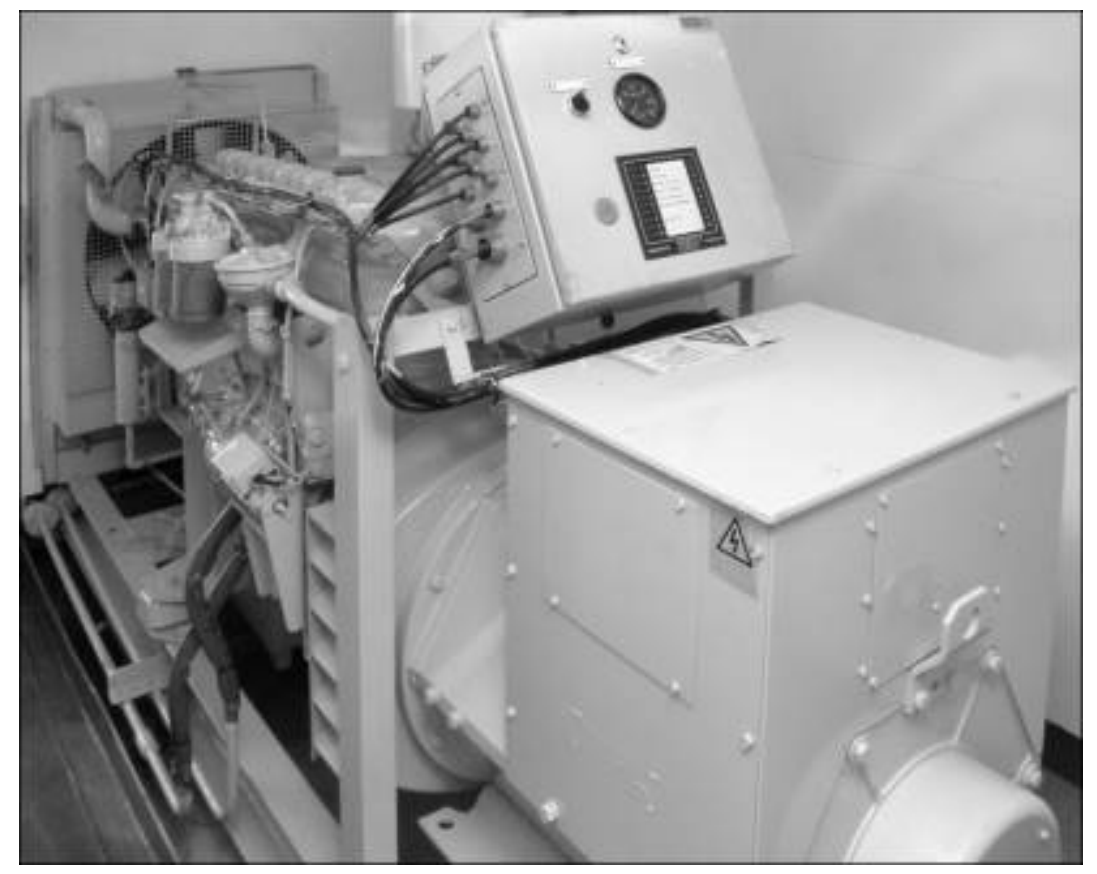

Figure 1: Emergency Power Plant - general view - photo.

In comparison with past 2D solutions (fig. 2), the new generation of such simulators consists of better graphical presentation (including 3D), closer relation between simulation and realism of machinery operation, and operation possibilities through control panel. Thus, it is evident that the difference between a 2D simulator and a 3D simulator is significant.

General view of 3D Emergency Power Plant simulator is shown on fig.3.

In this Emergency Power Plant simulator, 3D visualization has been applied. This simulator allows for the following features:

- selection of system's views (front, DO tank, emergency generator, switchboard and battery charger)

- zooming of selected parts of system's elements

- opening and closing the valves

- $\quad$ setting switched positions

- operation on push buttons 


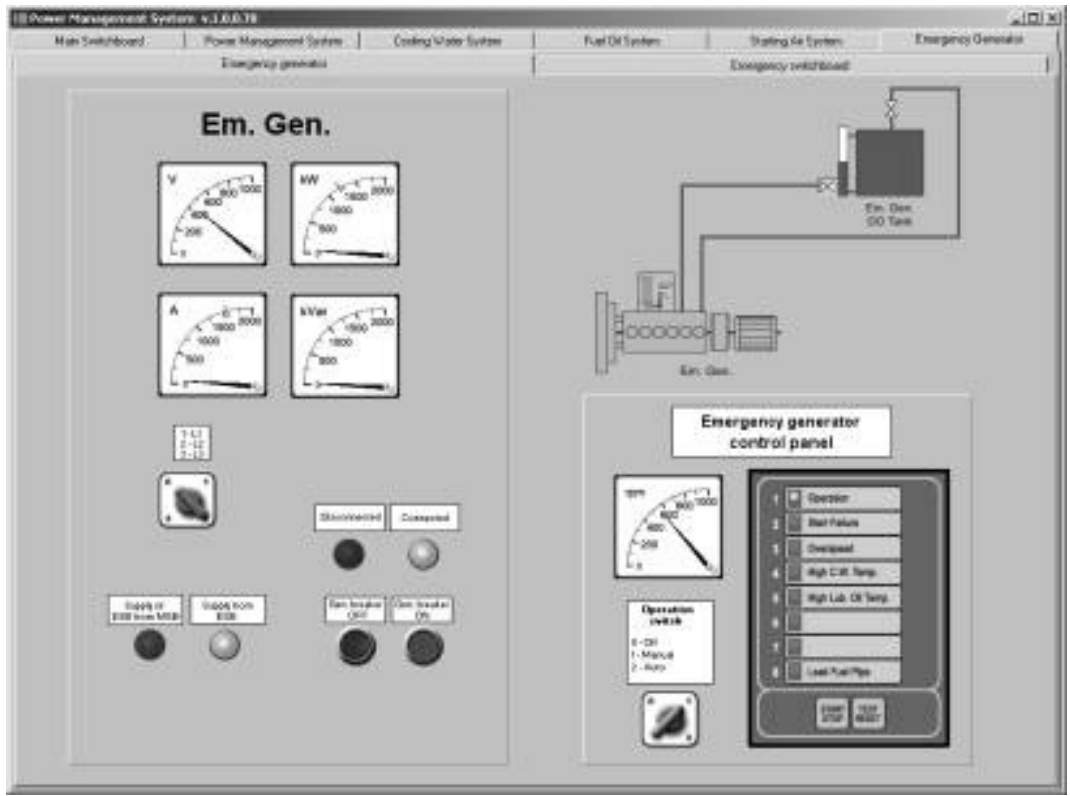

Figure 2: $\quad$ Emergency Power Plant as 2D simulator.

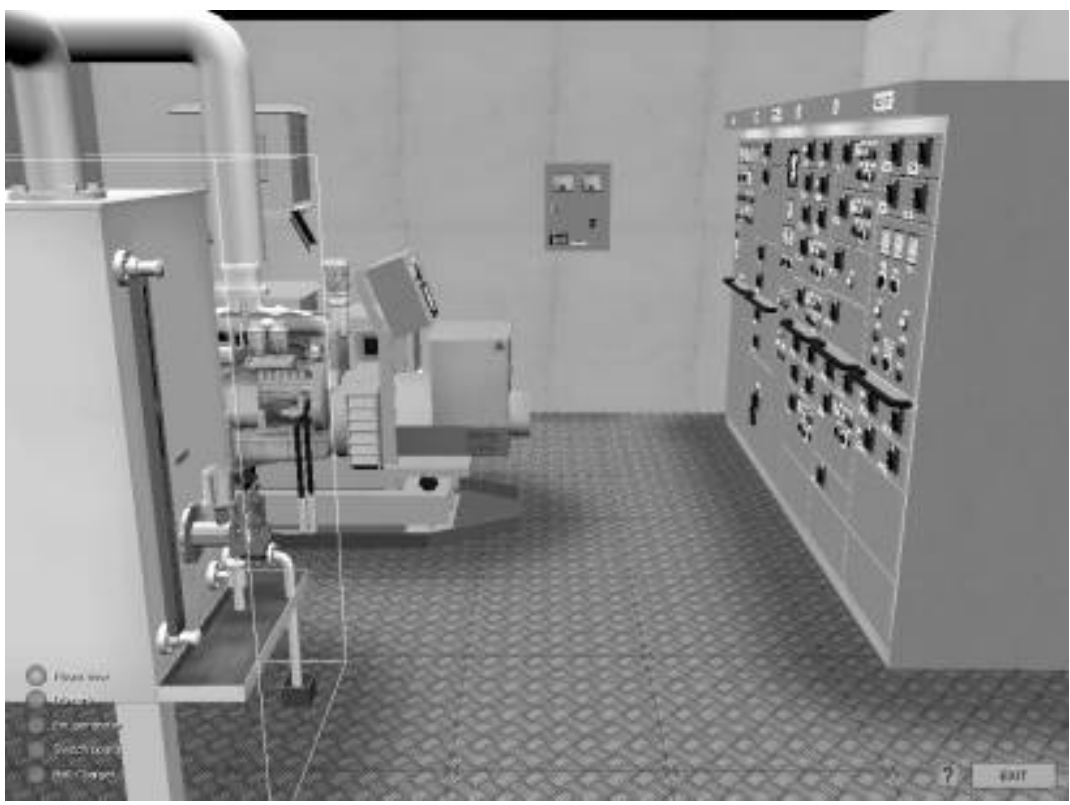

Figure 3: $\quad$ Emergency Power Plant - 3D simulator's general view. 
Additionally, simulator allows for valve's opening or closing - by mouse clicking - fig 4 . Zooming selection is marked by the lines surrounding the specific engine room element.

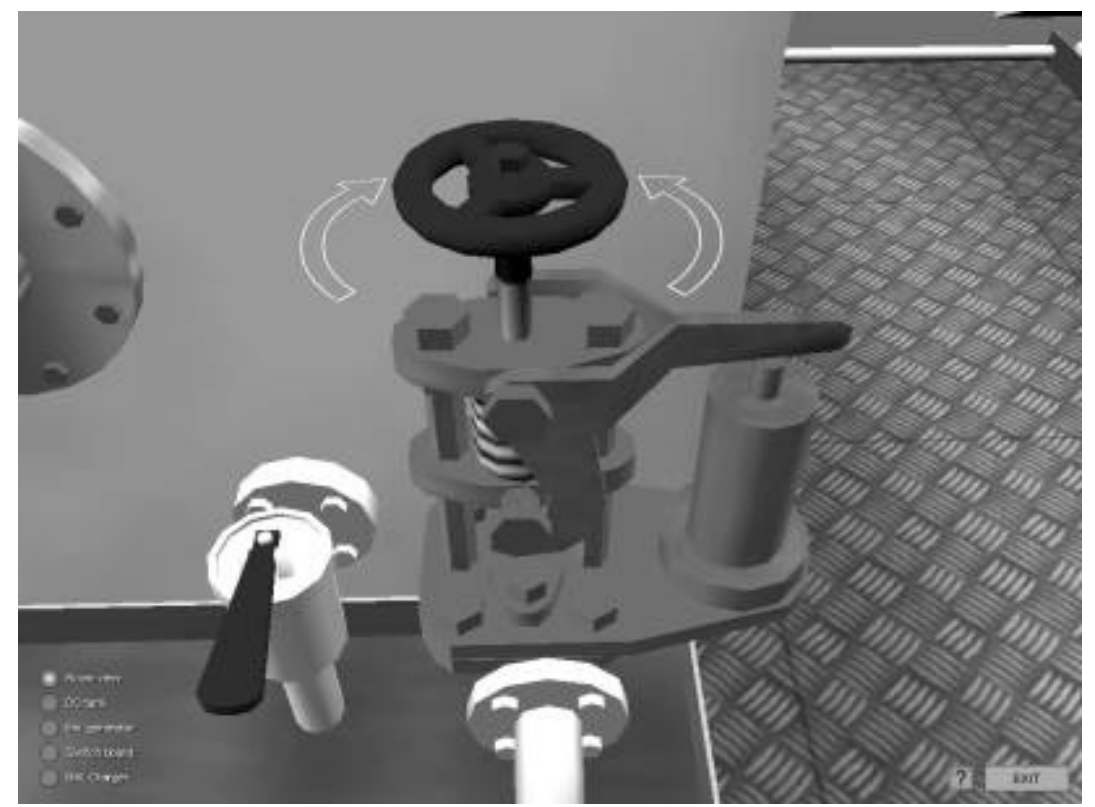

Figure 4: Fuel oil valve visualization.

Emergency Power Plant diesel engine view with control panel zoom selection is presented in fig. 5. The diesel engine's control panel, presented on Fig. 6, was intentionally designed to be as close as possible to the real equipment design.

Diesel engine starting procedure can be effectuated in two ways:

- from control panel with application of electrical starter (24 V available) - fig. 6

- $\quad$ by emergency hydraulic starter ( $24 \mathrm{~V}$ not available) - fig. 7

In case of diesel engine emergency operation, the trainee ought to create proper pressure in hydraulic bottle and start the engine by manual lever. Emergency hydraulic engine's starter is shown of fig. 7.

This simulator includes sound effects as in real life operation.

Electric switchboard presented on fig.8 includes:

- emergency generator panel - fig. 9

- shore supply panel

- Diesel engine' and battery charger control panel

- emergency supply receivers

- transformer's panel 


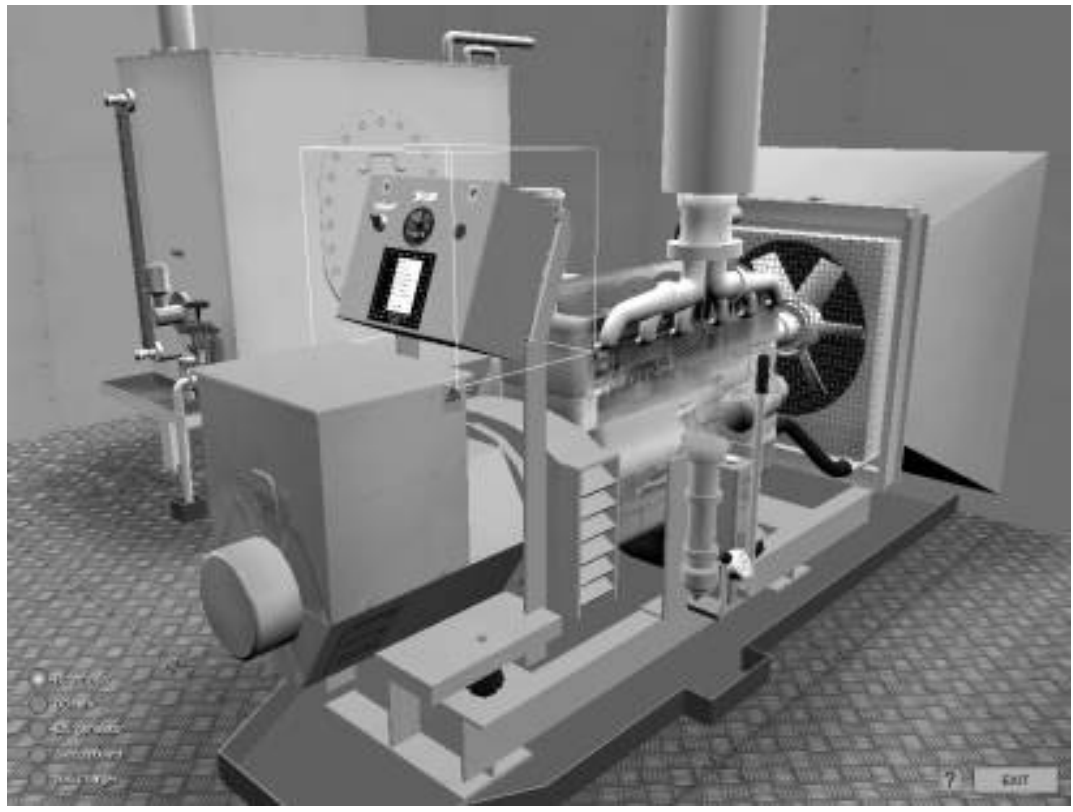

Figure 5: Emergency Power Plant simulator - Diesel engine with control panel zoom selection.

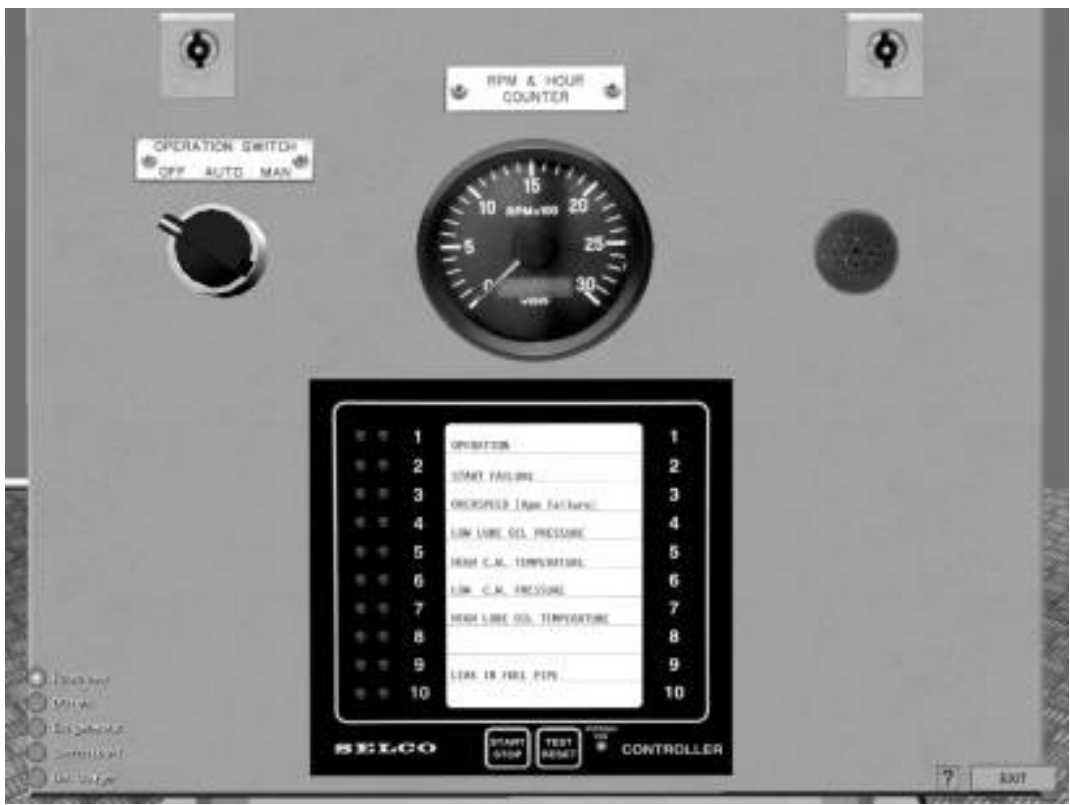

Figure 6: Control panel - zoom presentation. 


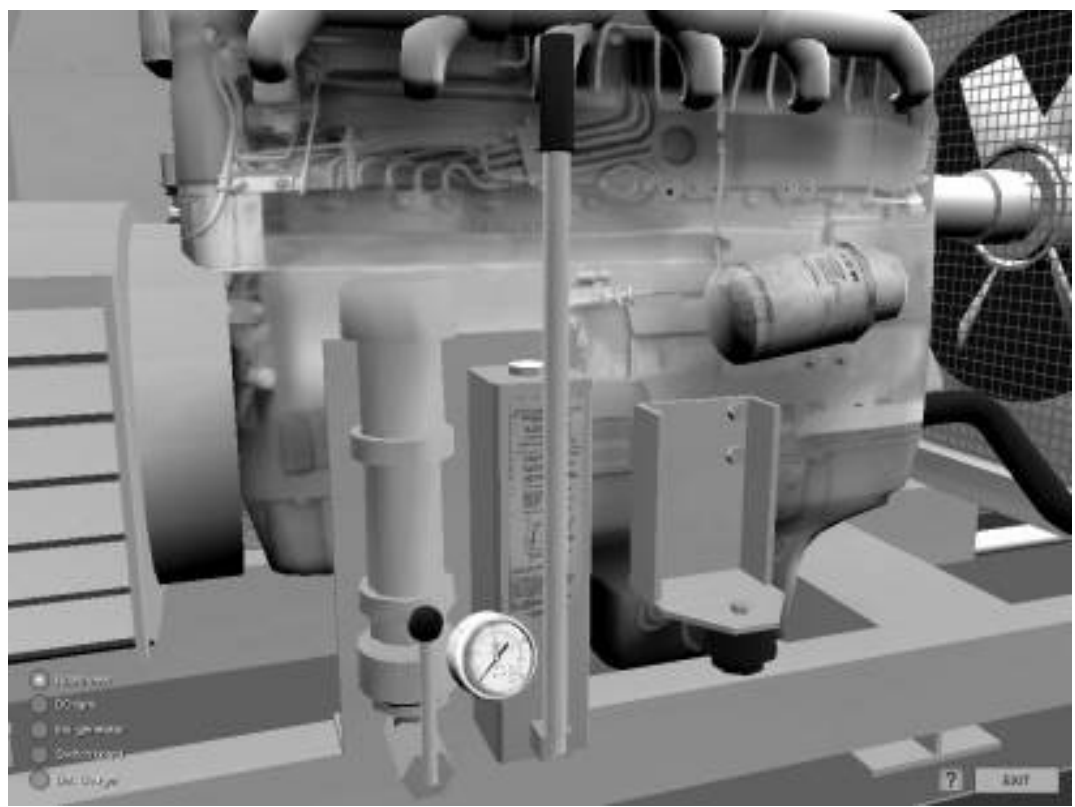

Figure 7: Emergency hydraulic engines' starter.

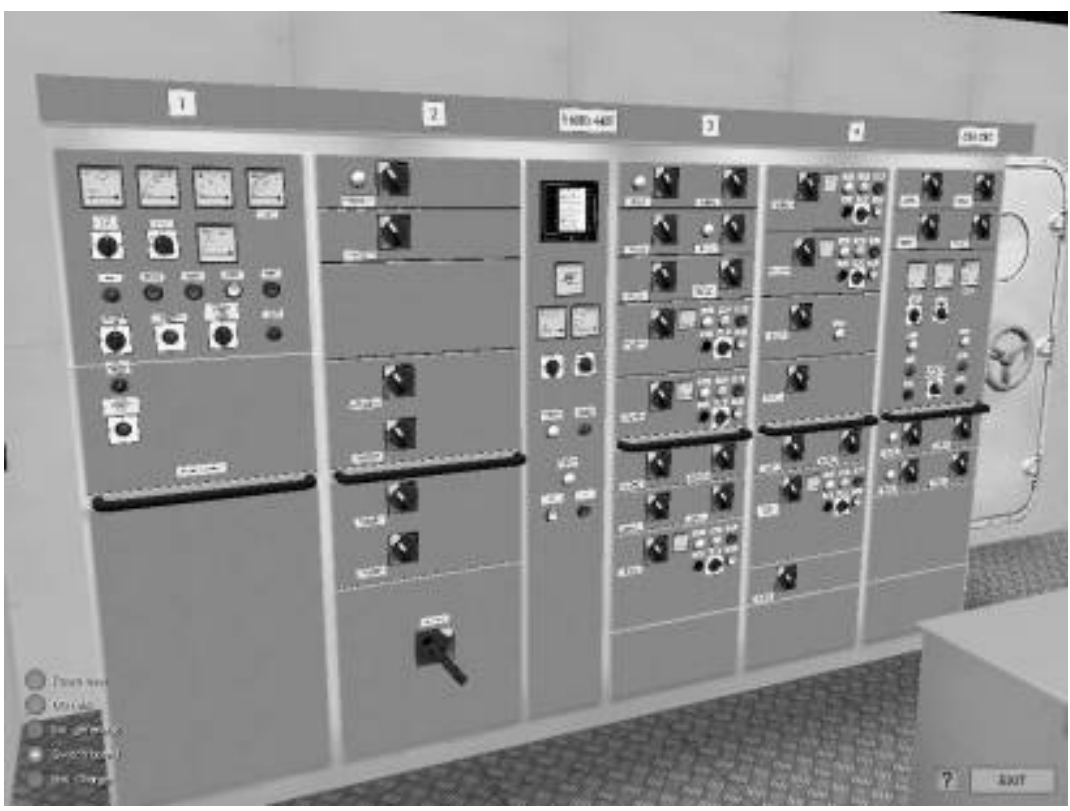

Figure 8: $\quad$ Emergency switchboard - general view with zoom selections. 


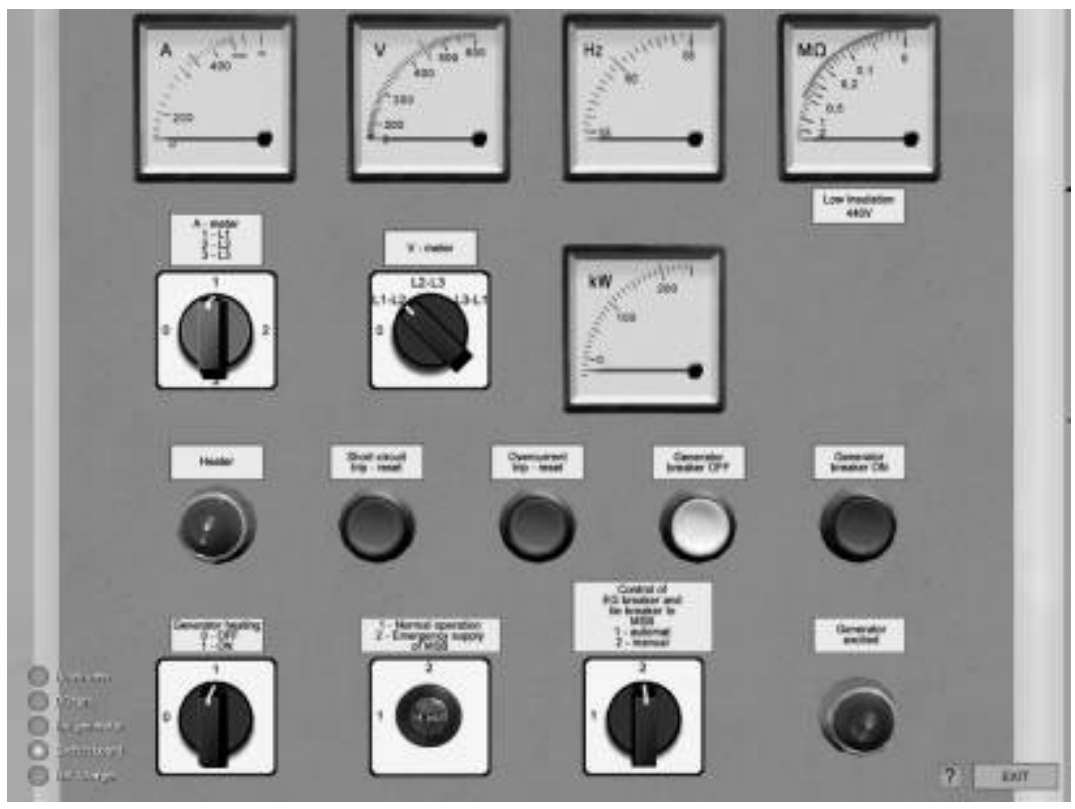

Figure 9: Zoomed emergency switchboard control panel.

\section{Conclusion}

As it has been mentioned above, proper navigation through the $3 \mathrm{D}$ simulator's elements is the key point in order to achieve the didactic purposes. The new concepts of view selection, zooming features of elements and operation by cursor and mouse clicking, as applied in Emergency Power Plant simulator, described in this paper, appears to be very effective and easily adaptable by trainees in practice.

Due to the specificity of operating marine equipment in real life conditions, the didactic goals in marine education are directly linked with achieving preparedness for emergency situations. Such preparedness may only be achieved if the trainee is familiar with both the equipment and its operating modes, including emergency situations. If the trainee has been trained only on simulators that are far from real machinery environment, his state of preparation for emergencies on board is not satisfactory.

$3 \mathrm{D}$ visualisation reduces the gap between operating marine machinery in simulation conditions and in real life. In the near future, this type of 3D solutions should be applied more and more often in engine room simulators design. The presented simulators are related to marine machinery, but the concept of composition and navigation through the system's elements can be easily applied for the purposes of any type of technical equipment and shall contribute in a similar manner to hazard prevention. 
To summarize, the application of engine room simulators with 3D visualization is a valuable hazard prevention tool as it reduces the level of human error in the operation and maintenance of marine equipment.

\section{References}

[1] R. Cwilewicz, L. Tomczak, Z.J. Pudlowski, Effective application of engine room simulators in marine engineering education, Proc. $3^{\text {rd }}$ Global Conference on Engineering Education, Glasgow, Scotland, United Kingdom, 2002, pp. 316-318.

[2] STCW - Standards of Training, Certification and Watchkeeping for Seafarers 78/95 Convention International Maritime Organization, London, 1996.

[3] R. Cwilewicz, L. Tomczak, The role of computer simulation programs for marine engineers in hazard prevention by reducing the risk of human error in the operation of marine machinery, Proc. $4^{\text {th }}$ International Conference on Computer Simulation in Risk Analysis and Hazard Mitigation - Risk Analysis IV, 2004, pp. 245-249.

[4] L. Tomczak, Practical aspects of 3D graphical applications in marine Engineering Education, Global Journal of Engineering Education, 9(2), 2005, pp.137-142.

[5] L. Tomczak, Application of 3D visualization in marine engine room simulators, Proc. $7^{\text {th }}$ International Conference on Engine Room Simulators (ICERS7), Portoroz, Slovenia, 2005, pp. 232-240. 